\title{
A multi-scale study of the interface between natural fibres and a biopolymer
}

\author{
Antoine Le Duigou ${ }^{a, *}$, Christophe Baley ${ }^{a}, Y^{\prime}$ ves Grohens ${ }^{a}$, Peter Davies ${ }^{b}$, Jean-Yves Cognard ${ }^{c}$, \\ Romain Créach'cadec ${ }^{\mathrm{c}}$, Laurent Sohier ${ }^{\mathrm{d}}$
}

\author{
a LIMAT B, Laboratoire d'Ingénierie des matériaux de Bretagne, Polymers and Composites, Université de \\ Bretagne Sud, Rue de Saint Maudé BP 92116, 56321 Lorient Cedex \\ ${ }^{b}$ IFREMER, Marine Structures laboratory, 29280 Plouzané \\ ${ }^{c}$ LBMS, ENSTA, 29806 Brest \\ d LBMS, Université de Bretagne Occidental 29285 Brest
}

\author{
*: Corresponding author: Antoine Le Duigou, Tel.: +33297874586 ; fax: +33297874588 ; email address : \\ antoine.le-duigou@univ-ubs.fr
}

\begin{abstract}
:
A significant recent development in the composite field is the appearance of biocomposites (biopolymers reinforced by plant fibres) which combine mechanical performance and low environmental impacts. However, to replace conventional composites a significant effort is needed to understand their mechanical behaviour under complex loading (both in-plane and out-of-plane). The interfacial behaviour (fibre/matrix) of these materials also requires particular attention in order to optimize mechanical properties. With this aim modified Arcan, transverse tension and microdroplet debonding tests have been performed on flax reinforced PLLA biocomposites, as very few data of this type are available.
\end{abstract}

The out-of-plane tensile and tensile-shear properties of these biocomposites are lower than those measured in shear. Manufacturing parameters, and particularly consolidation pressure, are critical for these materials. Out-of plane apparent shear strengths are similar to those from debonding tests. A common feature of the tests performed at the three scales is the appearance of fibre peeling.

Keywords : A natural fibre composites ; B interfacial properties ; B out-of-plane properties ; B microbond test

\section{Introduction}

High performance composites are used in many applications such as automotive, aeronautical and nautical structures. In addition to functional properties such as mechanical behaviour, information on environmental behaviour is increasingly being requested by designers, particularly when an eco-design is considered. A significant recent development in this area has been the appearance of biocomposites (biopolymers reinforced by plant fibres) which combine good mechanical performance and low environmental impacts. The latter can be significantly reduced when fibres such as flax reinforce a biosourced thermoplastic polymer such as PLA (poly(lactic acid) [1], [2], [3], [4], [5] and [6]. The inclusion of plant fibres is of particular benefit to reduce weight in transport applications [7].

However, in order to replace conventional composites (glass/Polypropylene or glass/polyester) a significant effort is needed in order to understand the mechanical behaviour of these biocomposites under complex loading, both in- and out-of-plane. The interfacial behaviour (fibre/matrix) of these materials also requires particular attention in order to optimise mechanical properties, as the extensive experience with glass fibres does not exist 
yet for these relatively new materials. Most of the published work on biocomposites is based on results from tests at a single scale, often macroscopic (tensile or flexure tests), which makes analysis of the interfacial phenomena very difficult, especially when the fibres are randomly dispersed. Alternatives, staying at the macroscopic scale, are to use special mechanical tests such as mode I delamination which are sensitive to the interface $[3,8]$, recording acoustic emission on tensile specimens to determine damage threshold values [9] or to work on particular lay-ups such as $\pm 45^{\circ}$ in order to favour interfacial damage mechanisms $[3,10-12]$. Another solution is to work at the ply scale (mesoscopic) in order to simplify the phenomena. For example, off-axis tensile tests (at 15, 30, 45, 60 and $90^{\circ}$ ) have been performed on unidirectional flax/Polyester [10, 13], hemp/PET [14] and flax/Epoxy [11] composites.

Direct information on fibre/matrix interface behaviour can be obtained at the microscopic scale using micro-mechanics tests (pull-out, microbond, fragmentation...). Various studies on fragmentation and microdroplet debonding have been performed to characterize the interface between a flax fibre and matrix resins such as epoxy [15, 16], polyester [17], polypropylene [18] and more recently polylactide (PLA) [19].

Combining these different approaches within the study of one system should help to improve the understanding of the mechanisms governing the interface behavior, and comparing different characterization methods should enable the strengths and weaknesses to be clarified [20]. However, to date few studies have worked with this multi-scale approach. Herrera franco et al. [21] examined the influence of silane treatments on Hennequen fibres (with a HDPE matrix) using macroscopic tests (Iosipescu shear and flexure), mesoscopic (tensile and transverse flexure on unidirectional specimens) and microscopic tests (fragmentation and pull-out). The results at each scale showed the same trends for the treatments, even though absolute values cannot be compared directly. In a similar way, Nam et al. [22] performed 
pull-out and longitudinal tension tests on composites with a PolyButylene Succinate matrix reinforced by coir fibres in order to evaluate the influence of an alkaline treatment.

Following on from those studies, the present paper proposes a multi-scale characterization of the properties of a biocomposite which is recyclable and compostable, based on a PLLA matrix reinforced by randomly dispersed flax fibres. The properties at the macroscopic scale will be evaluated using an original experimental set-up (the modified Arcan test) which allows loading in the through-thickness direction [23]. Transverse tensile tests combined with in-situ scanning electron microscope observation will be used at the mesoscopic level and microdroplet debonding tests complete the study at the microscopic scale.

2- Materials and Methods

\subsection{Material}

\subsubsection{Fibres}

All the samples were manufactured with flax fibres grown in France. Plants were subjected to dew retting before mechanical scutching and hackling.

For samples characterized with the Arcan fixture (macroscopic scale), flax fibres were organized into a randomly oriented in-plane mat structure. Flax mats were manufactured using a semi-industrial paper-making route [24]. Fibre length was $10 \pm 1 \mathrm{~mm}$, which results in a high aspect ratio $(\mathrm{L} / \mathrm{d} \approx 470)$ due to separation of fibre bundles during the process. However some fibre bundles remain in the mat. The weight per unit area of the flax mats was around $230 \mathrm{~g} / \mathrm{m}^{2}$ 
Unidirectional biocomposites (microscale scale) were manufactured with unidirectional flax ribbon with transverse knitted cotton yarn supplied by Biorenfort ${ }^{\circledR}$ (France). The areal weight of the UD flax was around $150 \mathrm{~g} / \mathrm{m}^{2}$.

\subsubsection{Matrix}

The bio-polymer matrix used for all the samples was Poly-L-(lactic) acid (PLLA) of molecular weight $\left(M_{n}\right) 63000 \mathrm{~g} / \mathrm{mol}$ produced by Natureworks ${ }^{\circledR}$.

\subsection{Composite manufacturing}

PLLA/flax mat composites were manufactured by the film stacking route. The stack of 6 PLLA extruded films and 5 flax mats was placed in a hot press $\left(\mathrm{T}=190^{\circ} \mathrm{C}\right)$ according to a protocol published previously [25]. Fibre fraction was $30 \%$ by weight corresponding to $26.5 \%$ by volume. Arcan samples were milled from the panel with the following geometry: $88 \times 24 \times 2$ $\mathrm{mm}^{3}$. Transverse tensile samples were also manufactured by film stacking with the same protocol with various fibre weight content $(20,30$ and $40 \%)$. The specimen geometry is that of the NF T 57-101 standard with a $25 \mathrm{~mm}$ width. Microbond specimens were prepared by placing a PLLA microdroplet on a single flax fibre. To obtain single fibres, flax bundle separation was performed under an optical microscope using tweezers for extraction. A fibre specimen was then bonded to a thin paper frame which has a central longitudinal slot of fixed gauge length $(10 \mathrm{~mm})$. Each specimen was then re-examined under a microscope to check the fibre diameter and microdroplet geometry. The variability of fibre cross-section must be considered when working at the micro-mechanics scale on natural fibres. We assume that the drop length is small enough $(<150 \mu \mathrm{m})$ to be able to neglect fibre diameter variation along the bonded length of the droplet. 
Heating time and cooling rate were kept constant $\left(\mathrm{t}_{190^{\circ} \mathrm{C}}=8 \mathrm{~min}\right.$ and Cooling $\left.=10^{\circ} \mathrm{C} / \mathrm{min}\right)$ for all manufacturing processes in order to limit different stress states and microstructure variations. It should be noted that no physical or chemical pre-treatments were used for any of the samples.

\section{2-3 Mechanical characterization}

\section{2-3-1 Modified Arcan test}

The modified Arcan fixture (Figure 1) was designed to analyze adhesives and bonded assemblies over a range of tensile/shear and compression/shear loads [26, 27]. The fixture is carefully positioned between the jaws of a test machine using articulated connections (Figure 1). The use of machined beaks reduces edge effects and stress concentrations [23]. Tests were performed under displacement control at $0.5 \mathrm{~mm} / \mathrm{min}$.

\section{Figure 1}

In order to analyze the movements of the assembly an image analysis system was used, based on image correlation (ARAMIS, GOM). This enables the behaviour of the adhesive and the composite to be identified. The biocomposite specimens were lightly abraded, then bonded to aluminium substrates using the procedure described previously [23]. Tests were performed with loads in three directions: 0,90 and $45^{\circ}$ as shown in figure 2. Five samples were tested for each loading condition.

Figure 2

2-3-2 Transverse tensile test 
Tensile tests were performed on the composites to investigate possible correlation with $0^{\circ}$ Arcan tests. They were carried out according to French standard NF T 57-101 on parallel sided specimens of width $25 \mathrm{~mm}$. Elongation was measured using an extensometer. Loading rate was $1 \mathrm{~mm} / \mathrm{min}$.

\subsubsection{Microdebonding tests}

In order to observe the damage mechanisms, samples were also tested on a small tensile test machine (DEBEN microtest) inside a scanning electron microscope (SEM), a Jeol JSM 6460LV.

The force and displacement were recorded during each test allowing an apparent interfacial shear strength (IFSS) to be determined. At least 50 microdroplets were tested in order to be able to apply a statistical approach. The load-displacement behaviour was linear for all tests up to debonding. An apparent interfacial shear strength $\tau_{\text {app }}$ (IFSS) was determined using simple micro-mechanics equations [28] which assumes a uniform interface stress distribution. The contribution of residual stresses and friction are not taken into account [29] even though friction strength after debonding is analysed separately. The interfacial shear strength will be compared to to pure shear $90^{\circ}$ Arcan tests.

\section{3- Results and Discussion}

\section{3-1 Arcan characterization}

The flax mat/PLLA bio-composite was characterized using the Arcan fixture and loading in 3 directions: tension $\left(0^{\circ}\right)$, shear $\left(90^{\circ}\right)$ and tension/shear $\left(45^{\circ}\right)$. Figures $3 \mathrm{~A}, \mathrm{~B}$ and $\mathrm{C}$ show the mechanical behaviour of each set of samples. 
Figure 3

For the through-thickness tensile tests the results from the different specimens show considerable scatter (Figure 3A). Three of the samples show an irreversible damage threshold (knee), the others are nearly linear up to failure. The slopes of force versus displacement are different but the break loads are all quite similar, around $6.5 \mathrm{kN}$ (Table 1). This gives an apparent failure strength of $9.4 \pm 0.4 \mathrm{MPa}$ (Table 1).

\section{Table 1}

Fracture surface observations indicate an intralaminar failure in the composite within the flax mat rather than at the epoxy adhesive joint (Figure 4A). Therefore the tests characterize the out-of-plane properties of the Flax/PLLA biocomposite, not the adhesive or interface. The fracture surfaces observed are similar to those revealed in a previous study on the same materials, after interlaminar crack propagation failure [3].

\section{Figure 4}

Fracture surface observations in a scanning electron microscope show there are some fibre bundles apparent as this is a prototype mat material. In addition, many fibres fail in a cohesive manner, within the outer fibre layers (Table 2). Control of the fibre/matrix interface is not the only challenge in these materials as the resistance of shared lamellae within fibre bundles and of the fibre layers to out-of-plane loads may be the weakest link. The observations also indicate quite ductile matrix behaviour, again confirming previous results [3]. At this scale, the fibre/matrix interface appears to be of good quality.

The response to shear loading $\left(90^{\circ}\right)$ shows little scatter (Figure 3B). A bi-linear behaviour is noted, the quasi-linear section extending from 0 to around $8000 \mathrm{~N}$, the damage threshold at which cracks appear and the stiffness decreases. From this point onwards the extension continues to increase, as other energy dissipating mechanisms exist (debonding, friction at the 
fibre/matrix interface, plastic deformation of the matrix...). The break strength in shear is around $19 \mathrm{MPa}$, twice the value obtained in tension (Table 1). Final failure occurs once again within the flax mat layer (Figure 4B). Different failure modes can be observed in the mat fibres due to the quasi-isotropic fibre orientation, but the majority of the fibres show a clean break (Table 2). There is some peeling but it is mostly very superficial. The matrix shows a different aspect to that of the $0^{\circ}$ fracture surfaces, with very little ductility apparent. However, there is some evidence of debonding, with the impressions of fibres left in the matrix after the fibres have been removed (Table 2). It should be noted that the displacements in shear are around 10 times larger than those measured in tension.

The plots from the tension-shear tests at $45^{\circ}$ (Figure 3C) also show little scatter. Here the biocomposites show a quasi-linear behaviour with brittle failure, the failure strains are in the same range as those measured during tensile loading at $0^{\circ}$. The failure strengths are also similar to the tensile strengths, around $9 \mathrm{MPa}$ (Table 1). Fracture surface observations (Figure 4C) indicate failure in the flax mat once again, with an intermediate failure between those observed at $0^{\circ}$ and $90^{\circ}$. Considerable peeling is noted, the matrix is similar to that observed in tension and the residual PLLA on the fibres suggests a reasonable fibre/matrix interface quality (Table 2).

Table 2

The results from the different loading combinations can be summarized in a plot showing a failure envelope such as the one presented in Figure 5.

Figure 5 
There are few data available for similar material in the published literature to compare with these results. However some recent studies with the same modified Arcan, fixture as the one used here, have characterized various structural adhesives [30, 31]. Apparent tensile failure stresses for these materials vary from 30 to $40 \mathrm{MPa}$ and shear strengths from 30 to $50 \mathrm{MPa}$. Finally, Sohier et al. [32] presented some values for $45^{\circ}$ glass/carbon/epoxy composites manufactured in an autoclave. The failure stresses in tension and shear were around $45 \mathrm{MPa}$, around 5 times the values for the biocomposites tested here.

3-2Mesoscopic scale: Transverse tension on unidirectional composite

Figure 6 shows the behaviour of PLLA composites reinforced by unidirectional flax reinforcement under transverse tensile loading for different fibre contents. For a $20 \%$ weight fraction $\left(\mathrm{v}_{\mathrm{f}}=17.2 \%\right)$, the biocomposite shows brittle behaviour. As the fibre content is increased the tensile behaviour tends to become non-linear. A similar trend has been noted previously for composites with flax fibres in a polyester matrix $\left(\mathrm{v}_{\mathrm{f}}=21.5 \%\right)$ [33]. One has to keep in mind that the unidirectional reinforcement includes both single fibres and bundles of fibres, which may induce strain field heterogeneity [34, 35].

Figure 6

Figures 7A and 7B show how the transverse modulus $\left(\mathrm{E}_{\mathrm{T}}\right)$ and transverse failure stress $\left(\sigma_{\mathrm{T}}\right)$ change with fibre content. The transverse modulus increases when fibres are added to the 
matrix (20\%) from $3600 \mathrm{MPa}$ to $4100 \mathrm{MPa}$. The transverse modulus of the flax fibres has been estimated to be slightly higher than that of the matrix $\left(5<\mathrm{E}_{\mathrm{fT}}<9 \mathrm{GPa}\right)[13,33]$.

However, increasing the fibre content from 20 to $40 \%$ results in a very small further increase in $\mathrm{E}_{\mathrm{T}}$. Again these results are similar to those measured on flax/polyester, and are significantly lower than those for glass/polyester [33].

The transverse failure stress drops sharply as fibres are added, from around 60MPa for the unreinforced matrix to around $30 \mathrm{MPa}$ for the composite with $20 \%$ by weight of fibres. This value is significantly higher than those reported for flax/polyester, glass/polyester [33]. The presence of fibres affects the strain field in the surrounding matrix, particularly when the fibre distribution is heterogeneous and fibre diameters vary [35]. The presence of both fibre bundles and single fibres results in a highly non-uniform strain field. Increasing fibre content from 20 to $40 \%$ results in only a slightly lower value of $\sigma_{\mathrm{T}}$.

\section{Figure 7}

Additional information on transverse damage in these biocomposites can be obtained by performing transverse tensile tests inside an SEM. Figures $8 \mathrm{~A}, \mathrm{~B}$ and $\mathrm{C}$ show different damage mechanisms during such tests.

Figure 8

Flax/PLLA biocomposites show different types of damage:

- In the matrix, in particular in the zones between fibres (Figures 8A and B), where the highest strain concentrations occur.

- Debonding at the fibre/matrix interface (Figures 8A et 4B) 
- Damage within the fibre bundle interfaces, in particular debonding between neighbouring lamella and between lamella and the matrix (Figure 8A). In these zones stress concentrations will occur. In addition to these areas, inside the bundle impregnation may not be complete especially with thermoplastics resins.

- Within the fibres themselves, by crack propagation (Figure 8C) or peeling of outer layers. Similar mechanisms have been noted in some carbon fibre (pitch based)/epoxy composites [36].

Therefore separation of fibre bundles in single fibres is of great importance to control damage mechanisms and to improve mechanical performance, as highlighted by Coroller et al .[34].

\section{3-3 Microdroplet debonding}

Microdroplet debonding tests were performed on the same materials in order to examine the apparent shear strength (IFSS) of the flax/PLLA interface directly. Typical flax/PLLA interface behavior is shown on figure $9 \mathrm{~A}$. The debonding force in this case is the maximum load required to break the fibre/matrix interface. The friction force is a residual force which

remains after debonding due to residual stresses. These two forces are plotted as a function of the bonded area (Figure 9B) in order to determine the apparent interfacial shear strength $\tau_{\text {app }}$ and the friction stress $\tau_{\mathrm{f}}$. The relationship between these two forces and the bonding area is quite linear.

\section{Figure 9}

The values of apparent shear strength and friction strength are 18.2 $\pm 1.2 \mathrm{MPa}$ and 8.2 \pm 1.9 $\mathrm{MPa}$ [37]. The friction strength is quite high, almost half the shear strength. The origins of 
this adherence between flax fibres and PLLA are now reasonably well known [19, 37-40].

The main contributors are van der waals forces, acid/base interactions, and capillary effects, in particular through the presence of hydroxyl groupes and water at the fibre surface and carbonyl groups in the PLLA. Clearly residual stresses also contribute to the strength of this interface, as well as friction energy dissipation between fibre and matrix.

Examination of failed debonded samples in the SEM (Figure $10 \mathrm{~A}$ and B) provides

indications of failure mechanisms. In most cases failure is interfacial, (Figure 10A), however, in a small number of cases surface peeling of the fibre is noted (Figure 10B) which can influence the friction behaviour [19].

Figure 10

4- Discussion

Examination of results from multi-scale testing such as those presented here can bring additional information on interfacial behaviour of flax/PLLA biocomposites. Table 3 summarizes the failure strengths from the modified Arcan, transverse tensile and debonding tests.

Table 3

It is interesting to note that the values from the Arcan shear test (macroscopic) and microdroplet debonding (microscopic) are similar. Both these tests load the fibre/matrix interface in shear. In addition, displacements recorded at the start of debonding during the microbond 
tests (around $0.05 \mathrm{~mm}$ ) are in the same range as the displacement corresponding to the loss of linearity in the Arcan shear test. Therefore, the large friction contribution measured after droplet debonding may also be one of the mechanisms contributing to the energy dissipation after the yield point in the Arcan shear tests which show a ductile failure mechanism (Figure 3B).

It should nevertheless be noted that the debonding test does not involve a pure shear stress state [41].

The transverse tension properties are significantly higher than those measured in the out of plane tension Arcan test at $0^{\circ}$. Although the response to both tests will involve loading of the fibre/matrix interface, the properties of the constituents and the reinforcement distribution also play a role [42]. The Arcan test at $0^{\circ}$ will also involve the interlaminar region, the quality of which depends on the consolidation during manufacture which differs from transverse tensile tests. The Arcan tensile specimen is also constrained over a much larger area, limiting Poisson effects

The tension-shear loading tests $\left(45^{\circ}\right.$ with Arcan) are more complex and difficult to relate to the other loadings, but are probably closer to most real loading situations. Analysis of results from tests at different scales is particularly complex for bio-composites, where the fibre distribution is very heterogeneous. This confirms observations published previously [3]. Fibre bundles introduce particular defects and can agglomerate during manufacture to result in clusters of fibre bundles. The multi-layer composite nature of the flax fibres themselves also makes the transfer between scales difficult to quantify. Nevertheless, at least qualitatively, certain phenomena such as fibre peeling are noted at each scale and would benefit from more study in order to establish to what extent the microscopic structure of flax fibres limits the macroscopic composite properties, in particular as an energy dissipation 
mechanism. This is also a key issue in the development of fibre surface treatments. Further work is in progress to pursue this.

\section{5- Conclusion}

The integration of vegetable fibres in a polymer matrix is enabling composites with interesting properties to be developed with a low environmental impact. In order to extend this development it is essential to possess a thorough understanding of the mechanical behaviour of these materials, not only in-plane but also in the through-thickness direction. With this aim modified Arcan, transverse tension and microdroplet debonding tests have been performed, as very few data of this type are available.

The out-of-plane tensile and tensile-shear properties of these biocomposites are lower than those measured in shear. Manufacturing parameters, and particularly consolidation pressure, are critical to obtain good impregnation without fibre degradation. Out-of plane apparent shear strengths are similar to those from debonding tests. A common feature of the tests performed at the three scales is the appearance of fibre peeling. This is an unusual failure mechanism, rarely observed in traditional composites, and indicates that a better understanding of the role of flax fibre micro-structure is essential if biocomposite properties are to be optimized.

Acknowledgements.

The authors wish to acknowledge the BResMat (Bretagne Réseau Matériaux) network for funding 


\section{References}

[1] Le Duigou A, Davies P, Baley C. Replacement of glass/unsaturated polyester composites by flax/PLLA biocomposites : Is it justified ? J biobased mater bioenerg. 2012;5:466-82.

[2] Bodros E, Pillin I, Montrelay N, Baley C. Could biopolymers reinforced by randomly scattered flax fibre be used in structural applications? Composites Science and Technology. 2007;67:462-70. [3] Le Duigou A, Davies P, Baley C. Macroscopic analysis of interfacial properties of flax/PLLA biocomposites. Composites Science and Technology. 2010;70:1612-20.

[4] Bax B, Müssig J. Impact and tensile properties of PLA/Cordenka and PLA/flax composites. Composites Science and Technology. 2008;68:1601-7.

[5] Oksman K, Skrifvars M, Selin J-F. Natural fibres as reinforcement in polylactic acid (PLA) composites. Composites Science and Technology. 2003;63:1317-24.

[6] Roussière F, Baley C, Godart G, Burr D. Compressive and Tensile Behaviours of PLLA Matrix Composites Reinforced with Randomly Dispersed Flax Fibres. Applied composite Material. 2011:1-18. [7] Joshi SV, Drzal LT, Mohanty AK, Arora S. Are natural fiber composites environmentally superior to glass fiber reinforced composites? Composites Part A: Applied Science and Manufacturing. 2004;35:371-6.

[8] Wong S, Shanks R, Hodzic A. Mechanical Behavior and Fracture Toughness of Poly(L-lactic acid)Natural Fiber Composites Modified with Hyperbranched Polymers. Macromolecular Materials and Engineering. 2004;289:447-56.

[9] Le Duigou A, Davies P, Baley C. Seawater aging of Flax/PLLA biocomposite. Polymer Degradation and Stability. 2009;94:1151-62.

[10] Gning PB, Liang S, Guillaumat L, Pui WJ. Influence of process and test parameters on the mechanical properties of flax/epoxy composites using response surface methodology. Journal of Materials Science. 2011;46:6801-11.

[11] Cichocki Jr. FR, Thomason JL. Thermoelastic anisotropy of a natural fiber. Composites Science and Technology. 2002;62:669-78.

[12] Romhány G, Kocsis J, Czigány T. Tensile Fracture and Failure Behavior of Thermoplastic Starch with Unidirectional and Cross-Ply Flax Fiber Reinforcements. Macromolecular Materials and Engineering. 2003;288:699-707.

[13] Shah DU, Schubel PJ, Clifford MJ, Licence P. The tensile behavior of off-axis loaded plant fiber composites: An insight on the nonlinear stress-strain response. Polymer Composites. 2012;33:1494504.

[14] Madsen B, Hoffmeyer P, Lilholt $\mathrm{H}$. Hemp yarn reinforced composites - II. Tensile properties. Composites Part A: Applied Science and Manufacturing. 2007;38:2204-15.

[15] Le Duigou A, Davies P, Baley C. Exploring durability of interfaces in flax fibre/epoxy microcomposites. Composites Part A: Applied Science and Manufacturing. 2013.

[16] Joffe R, Andersons J, Wallström L. Interfacial shear strength of flax fiber/thermoset polymers estimated by fiber fragmentation tests. Journal of Materials Science: Springer Netherlands; 2005. p. 2721-2.

[17] Baley C, Busnel F, Grohens Y, Sire O. Influence of chemical treatments on surface properties and adhesion of flax fibre-polyester resin. Composite Part A: Applied Science and Manufacturing.

2006;37:1626-37.

[18] Awal A, Cescutti G, Ghosh SB, Müssig J. Interfacial studies of natural fibre/polypropylene composites using single fibre fragmentation test (SFFT). Composites Part A: Applied Science and Manufacturing. 2011;42:50-6.

[19] le Duigou A, Bourmaud A, Balnois E, Davies P, Baley C. Improving the interfacial properties between flax fibres and PLLA by a water fibre treatment and drying cycle. Industrial Crops and Products. 2012;39:31-9.

[20] Herrera-Franco P, Drzal L. Comparison of methods for the measurement of fibre/matrix adhesion in composites. Comp Sci Technol. 1992;23:2-27. 
[21] Herrera-Franco PJ, Valadez-González A. Mechanical properties of continuous natural fibrereinforced polymer composites. Composites Part A: Applied Science and Manufacturing. 2004;35:339-45.

[22] Nam TH, Ogihara S, Tung NH, Kobayashi S. Effect of alkali treatment on interfacial and mechanical properties of coir fiber reinforced poly(butylene succinate) biodegradable composites.

Composites Part B: Engineering. 2011;42:1648-56.

[23] Cognard JY, Sohier L, Davies P. A modified Arcan test to analyze the behavior of composites and their assemblies under out-of-plane loadings. Composites Part A: Applied Science and Manufacturing. 2011;42:111-21.

[24] Le Duigou A, Deux J-M, Davies P, Baley C. PLLA/Flax Mat/Balsa Bio-Sandwich Environmental Impact and Simplified Life Cycle Analysis. Appl Compos Mater: Springer Netherlands; 2012. p. 1-16. [25] Le Duigou A, Davies P, Baley C. Seawater ageing of Flax/PLLA biocomposites. Polym Degrad and Stab. 2009;94.

[26] Cognard J, Creachcadec R, Sohier L. Strategies and the analysis of the behaviour of an Adhesive in bonded Assemblies. Journal of Engineering Materials and Technology. 2011;133.

[27] Cognard J, Sohier L, Jousset P, R C, Rachik M. Experimental analysis of the mechanical behaviour of a ductile adhesive in a bonded joint under proportional tensile-shear loads,. Chapter 1, Adhesives: Types, Mechanics and Applications (on invitation only), NovaPublisher's book, Eds J S Doyle \& R C O'Quinn, ISBN: 978-1-61324-703-72012. 2011:1-45.

[28] Miller B. A microbond method for determination for determination of the shear strength of a fiber/resin interface. Comp Sci Technol. 1987;28:17-32.

[29] Novak J, Pearce C, Grassl P, Yang L, Thomasson J. Analysis of the microbond test using non linear fracture mechanics. In: 17th International Conference on Composite Materials, ICCM17. 2009; Edinburgh, UK.

[30] Cognard J, Davies P, Gineste B, Sohie L. Development of an improved adhesive test method for composite assembly design. Composites Science \& Technology. 2005;65:359-68.

[31] Bordes M, Davies P, Cognard J-Y, Sohier L, Sauvant-Moynot V, Galy J. Prediction of long term strength of adhesively bonded steel/epoxy joints in sea water. International Journal of Adhesion and Adhesives. 2009;29:595-608.

[32] Sohier L, Cognard JY, Davies P. Experimental study of the behaviour of bonded assemblies of composites under out-of-plane loadings. Proceeding of 17 th Journée National des Composites (JNC)Poitiers. 2011.

[33] Baley C, Perrot Y, Busnel F, Guezenoc H, Davies P. Transverse tensile behaviour of unidirectional plies reinforced with flax fibres. Materials Letters. 2006;60:2984-7.

[34] Coroller G, Lefeuvre A, Le Duigou A, Bourmaud A, Ausias G, Gaudry T, et al. Effect of flax fibres individualisation on tensile failure of flax/epoxy unidirectional composite. Composites Part A: Applied Science and Manufacturing. 2013.

[35] de Kok JMM, Meijer HEH. Deformation, yield and fracture of unidirectional composites in transverse loading: 1. Influence of fibre volume fraction and test-temperature. Composites Part A: Applied Science and Manufacturing. 1999;30:905-16.

[36] Baral N, Guezenoc H, Davies P, Baley C. High modulus carbon fibre composites: Correlation between transverse tensile and mode I interlaminar fracture properties. Materials Letters.

2008;62:1096-9.

[37] Le Duigou A, Davies P, Baley C. Interfacial bonding of flax/Poly(L-Lactide) biocomposites. Composites Science and Technology. 2010;70:231-9.

[38] Raj G, Balnois E, Baley C, Grohens Y. Role of polysaccharides on mechanical and adhesion properties of flax fibres in flax/PLA biocomposite. International Journal of Polymer Science. 2011;2011.

[39] Raj G, Balnois E, Baley C, Grohens Y. Adhesion force mapping of raw and treated flax fibres using AFM force-volume. Journal of scanning probe microscopy. 2009;4:66-72. 
[40] Raj G, Balnois E, Baley C, Grohens Y. Probing cellulose/polylactic acid interactions in model biocomposite by colloidal force microscopy. Colloids and Surfaces A: Physicochemical and Engineering Aspects. 2009;352:47-55.

[41] Day RJ, Rodrigez JVC. Investigation of the micromechanics of the microbond test. Composites Science and Technology. 1997;58:907-14.

[42] de Kok JMM, Peijs T. Deformation, yield and fracture of unidirectional composites in transverse loading: 2. Influence of fibre-matrix adhesion. Composites Part A: Applied Science and Manufacturing. 1999;30:917-32.

\section{Figure caption}

Figure 1 Modified Arcan test set-up

Figure 2 Representation of the assembly and loading directions

Figure 3 Mechanical behaviour of flax mat/PLLA biocomposites under out-of-plane loads, - A tension $\left(0^{\circ}\right)$, B shear $\left(90^{\circ}\right)$ and $\mathrm{C}$ tension/shear $\left(45^{\circ}\right)$

Figure 4 Observation of biocomposite fracture surfaces, indicating failure within the flax mat. A : Loading at $0^{\circ}$. B : $90^{\circ} . \mathrm{C}: 45$

Figure 5 Failure envelope, out of plane loads, for flax mat/PLLA

Figure 6 Transverse stress-strain curve for PLLA/UD Flax biocomposites as a function of fibre weight content

Figure 7 Evolution of transverse Young's modulus (A) and transverse failure stress (B) of flax/PLA biocomposite versus fibre content

Figure 8 SEM images of damage mechanisms during transverse tensile tests in SEM. A: fibre bundles, B: region between single fibres, $\mathrm{C}$ : focus on a single fibre. Red arrows indicate loading direction

Figure 9 A Typical debonding behavior. B - Debonded Force and Friction force versus embedded surface

Figure 10 SEM Micrograph of debonded PLLA microdroplet on single flax fibre. A Interfacial failure. B Heterogeneous cohesive failure 

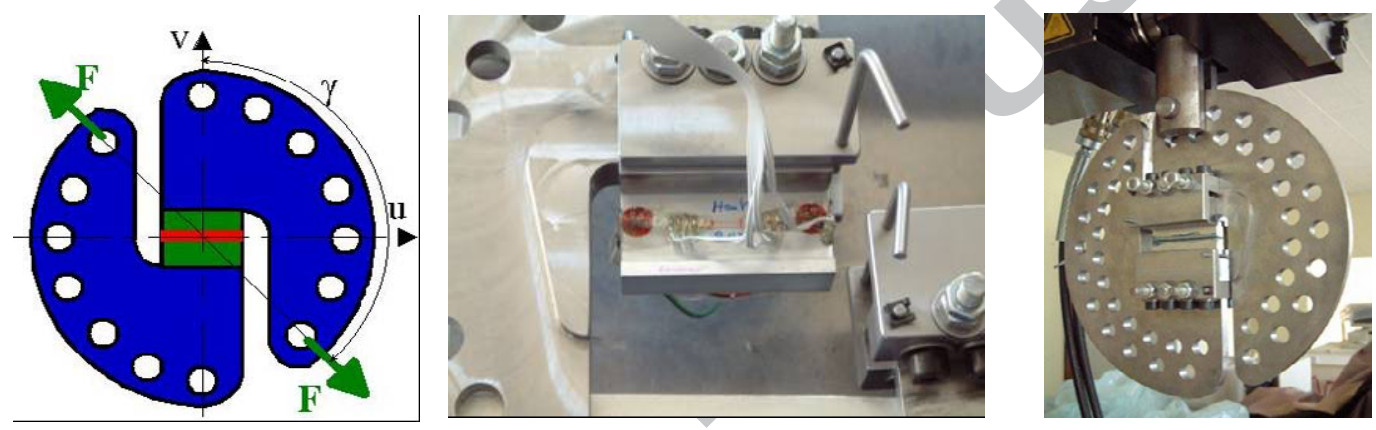

Figure 1 Modified Arcan test set-up 

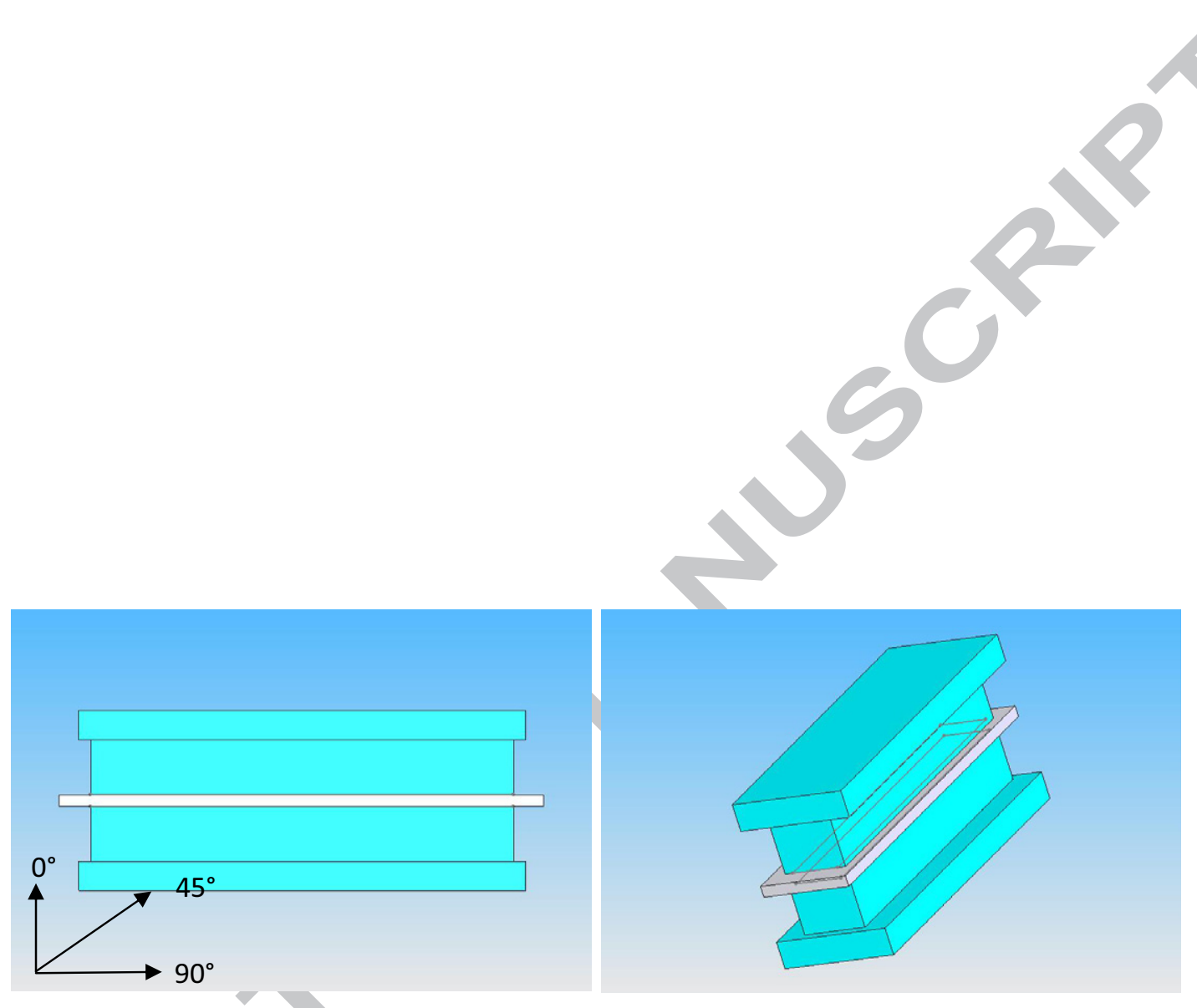

Figure 2 Representation of the assembly and loading directions 

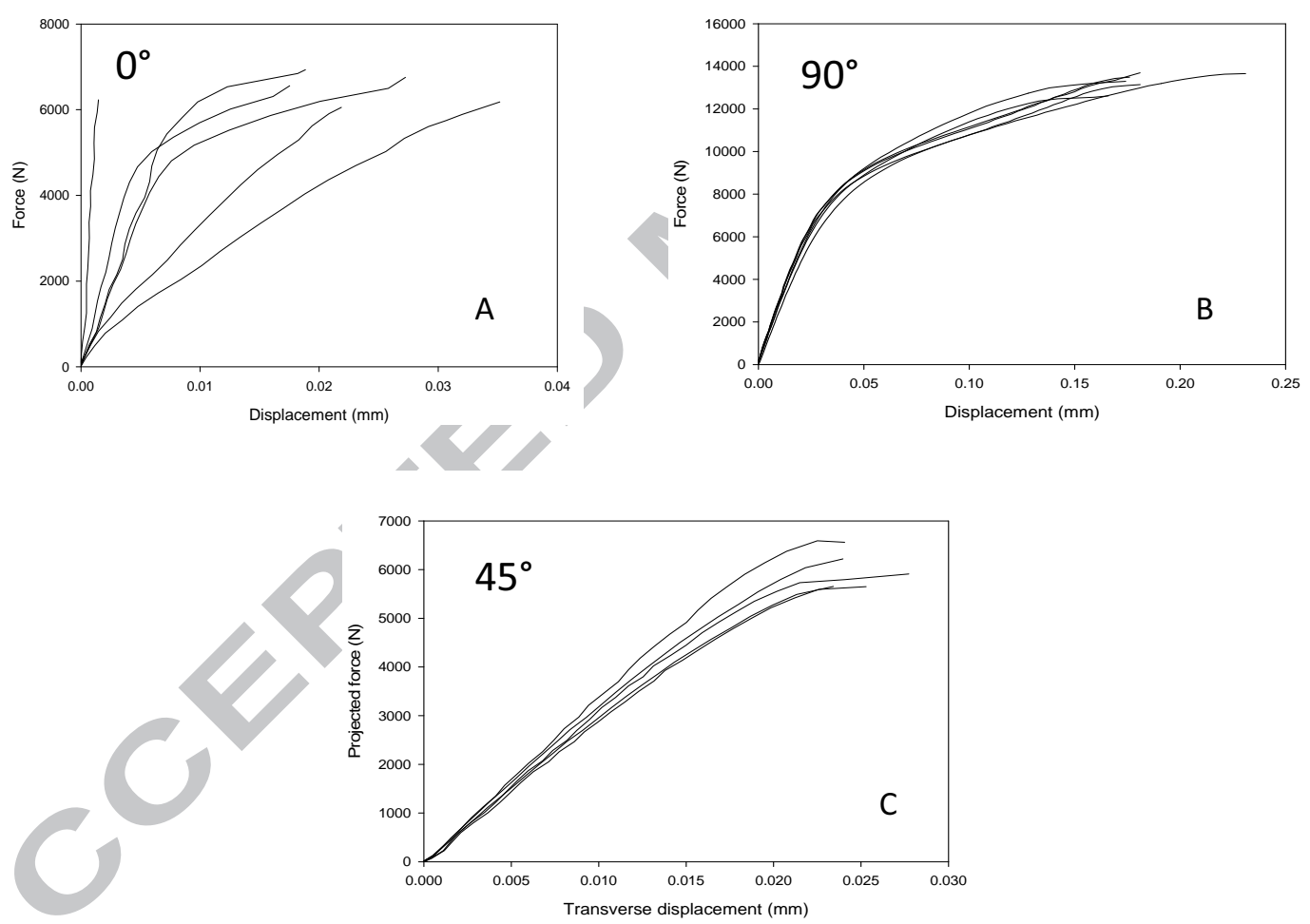

Figure 3 Mechanical behaviour of flax mat/PLLA biocomposites under out-of-plane loads, - A tension $\left(0^{\circ}\right)$, B shear $\left(90^{\circ}\right)$ and $\mathrm{C}$ tension/shear $\left(45^{\circ}\right)$ 


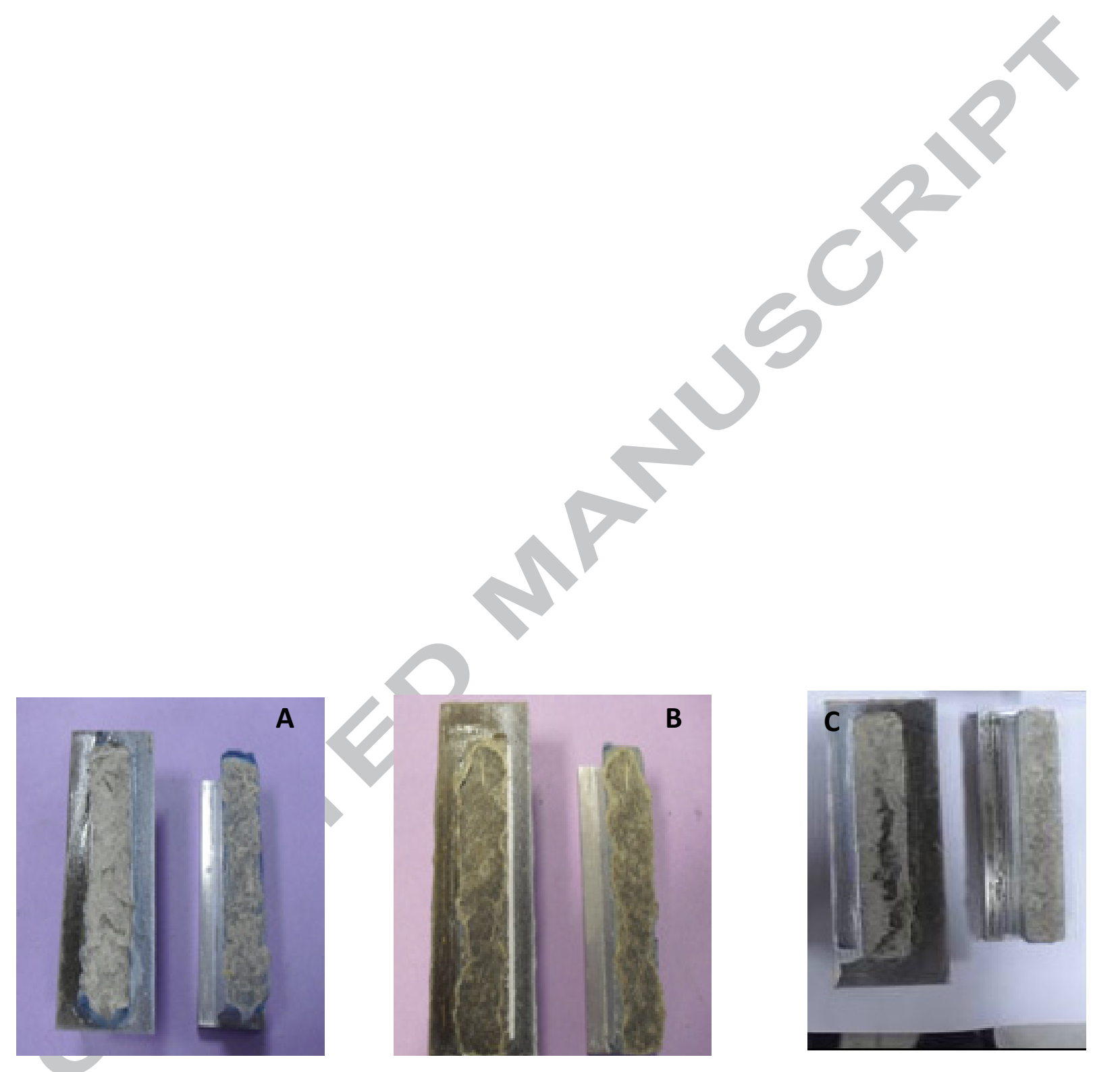

Figure 4 Observation of biocomposite fracture surfaces, indicating failure within the flax mat. A : Loading at $0^{\circ}$. B : $90^{\circ}$. C : $45^{\circ}$ 


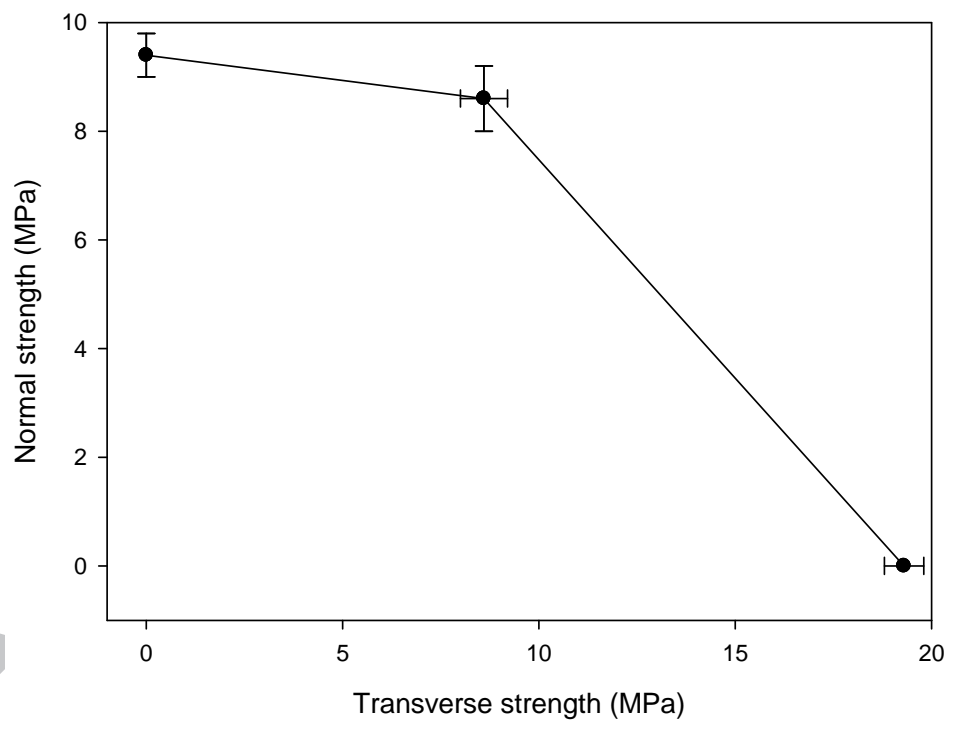

Figure 5 Failure envelope, out of plane loads, for flax mat/PLLA 

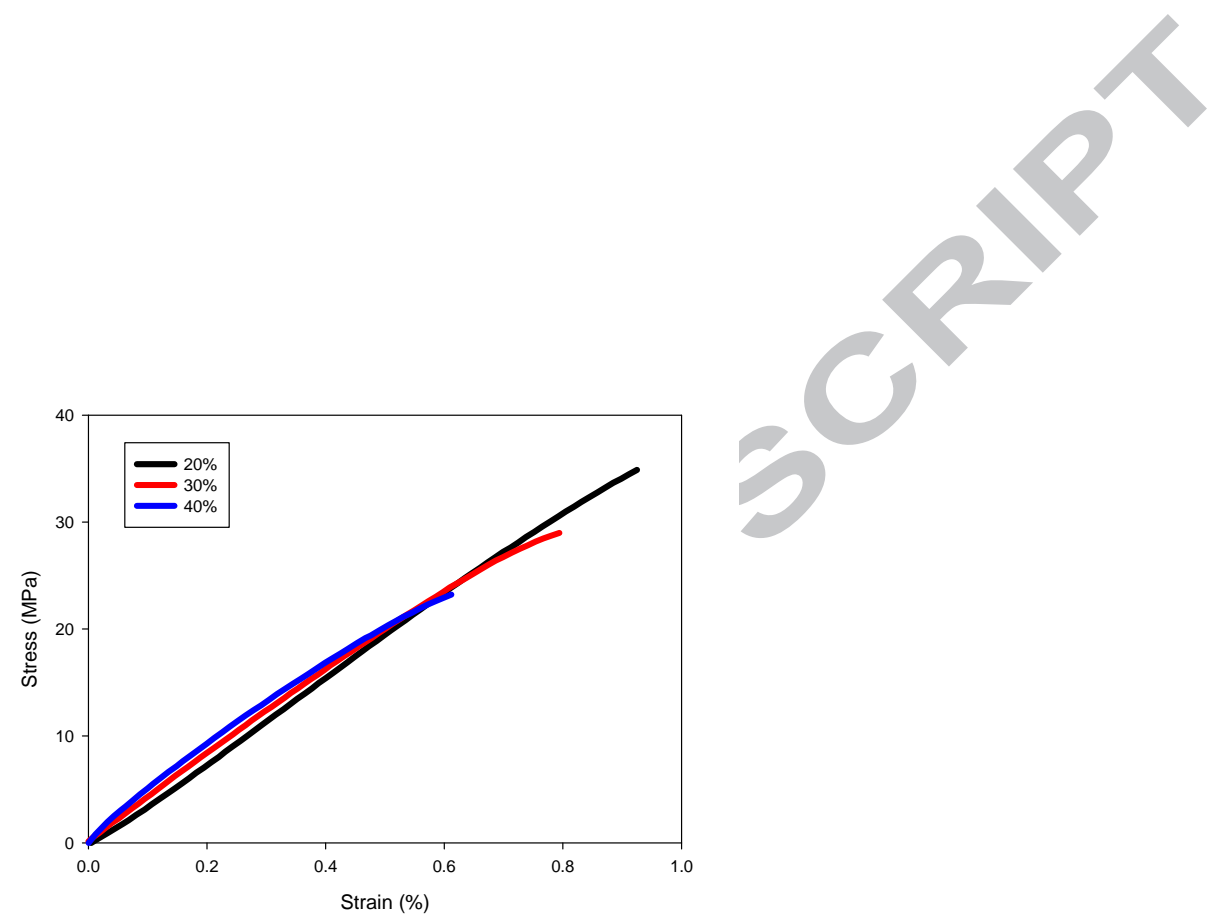

Figure 6 Transverse stress-strain curve for PLLA/UD Flax biocomposites as a function of fibre weight content 

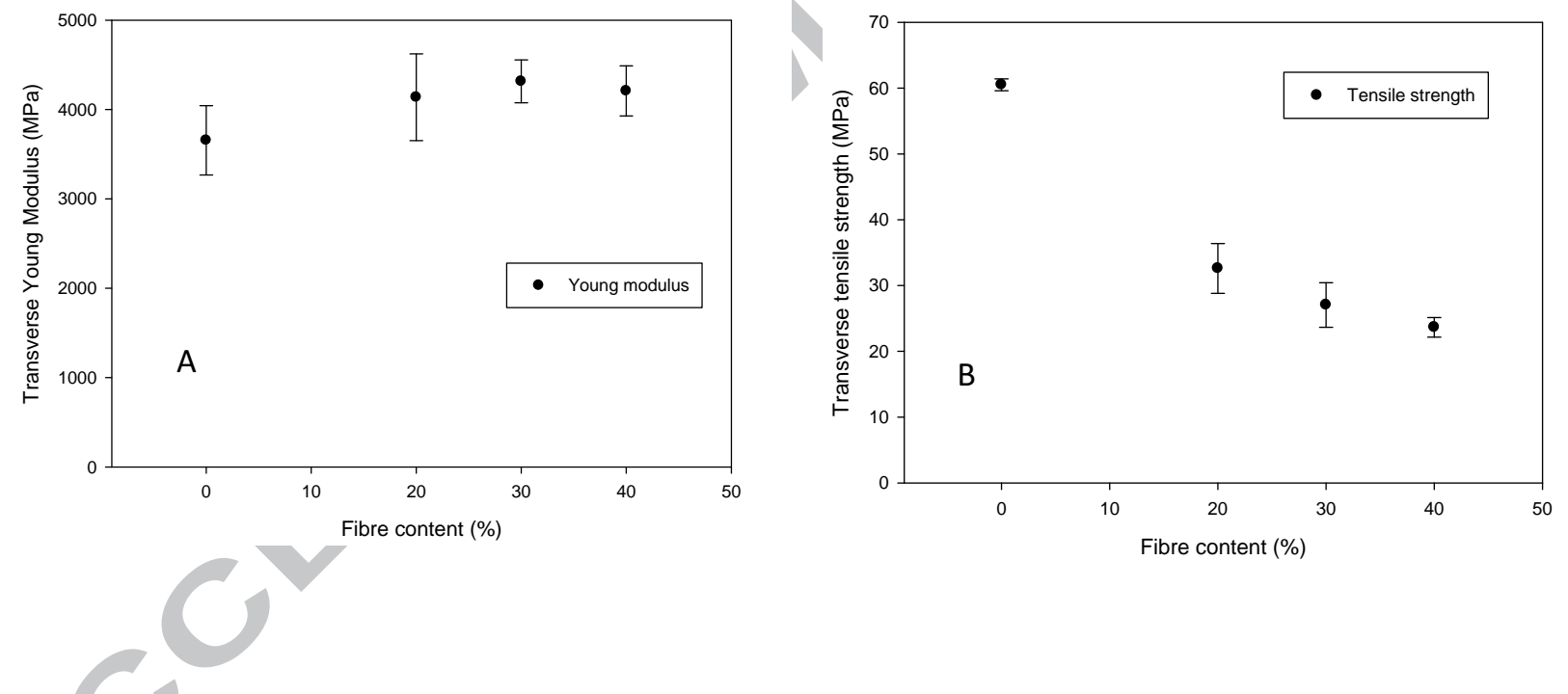

Figure 7 Evolution of transverse Young's modulus (A) and transverse failure stress (B) of flax/PLA biocomposite versus fibre content 


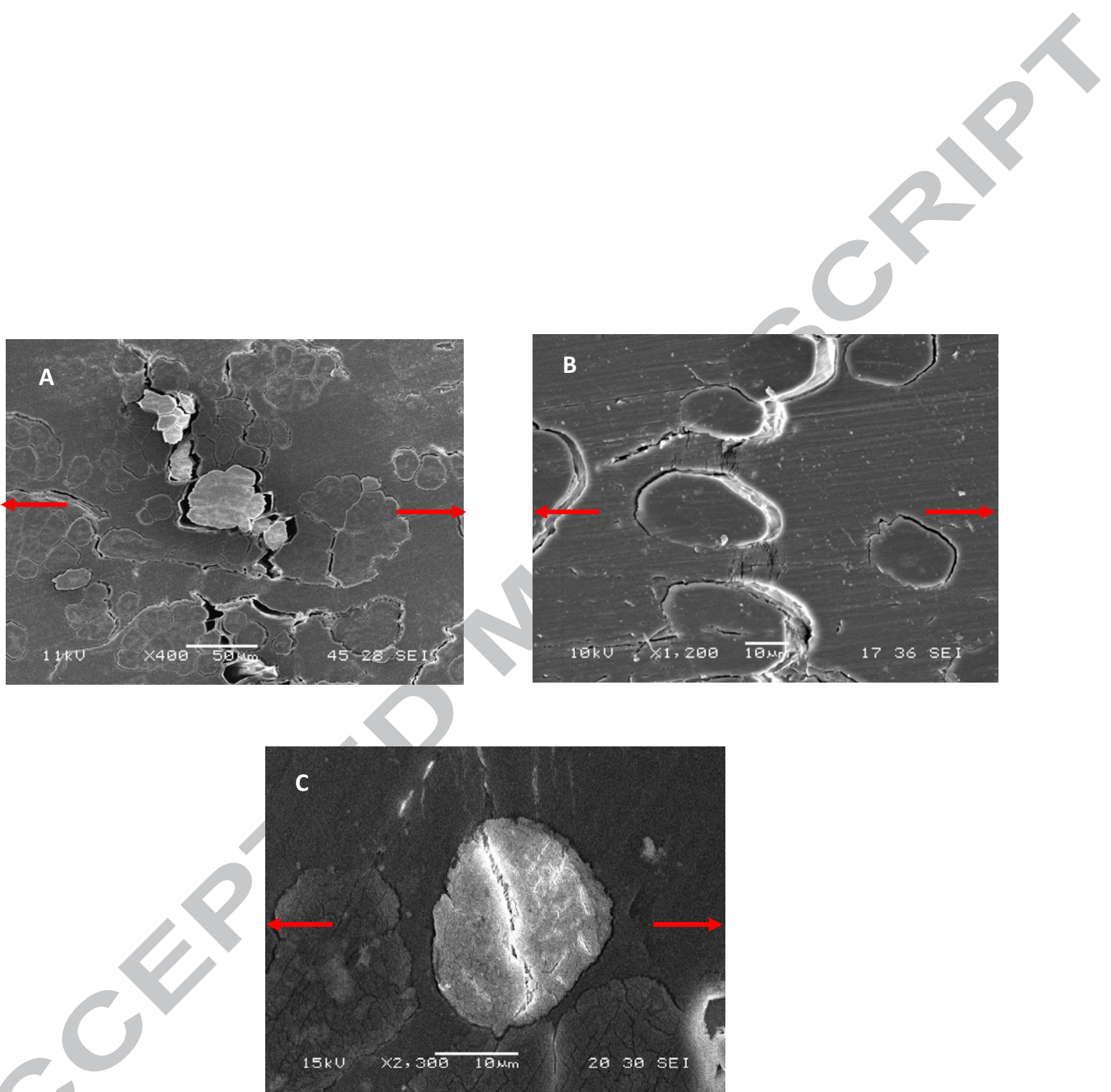

Figure 8 SEM images of damage mechanisms during transverse tensile tests in SEM. A: fibre bundles, B: region between single fibres. C: focus on a single fibre. Red arrows indicate loading direction 

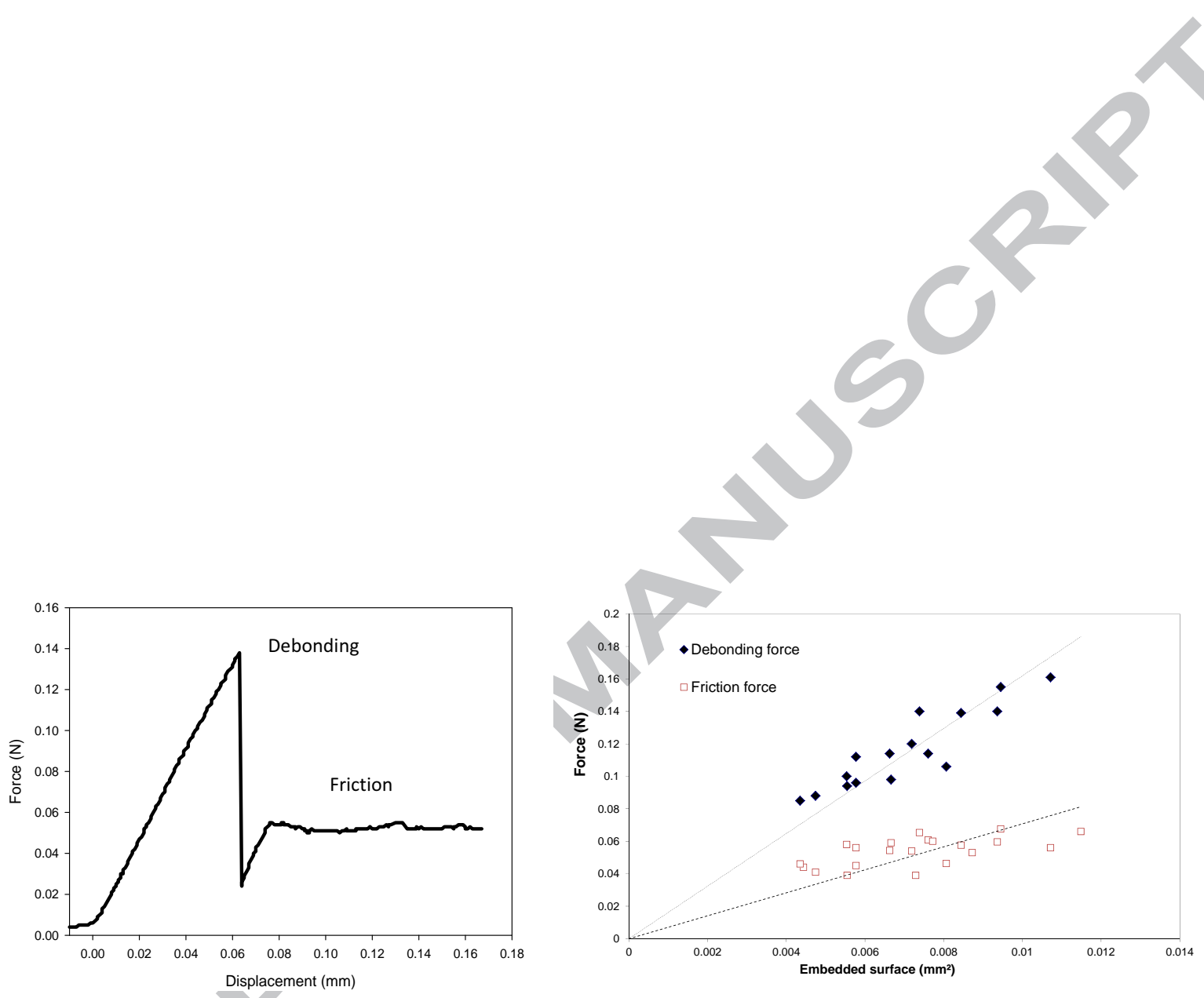

Figure 9 A- Typical debonding behavior. B- Debonded Force and Friction force versus embedded surface

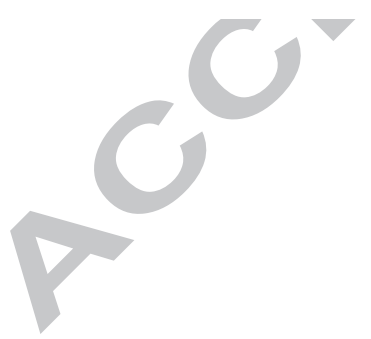



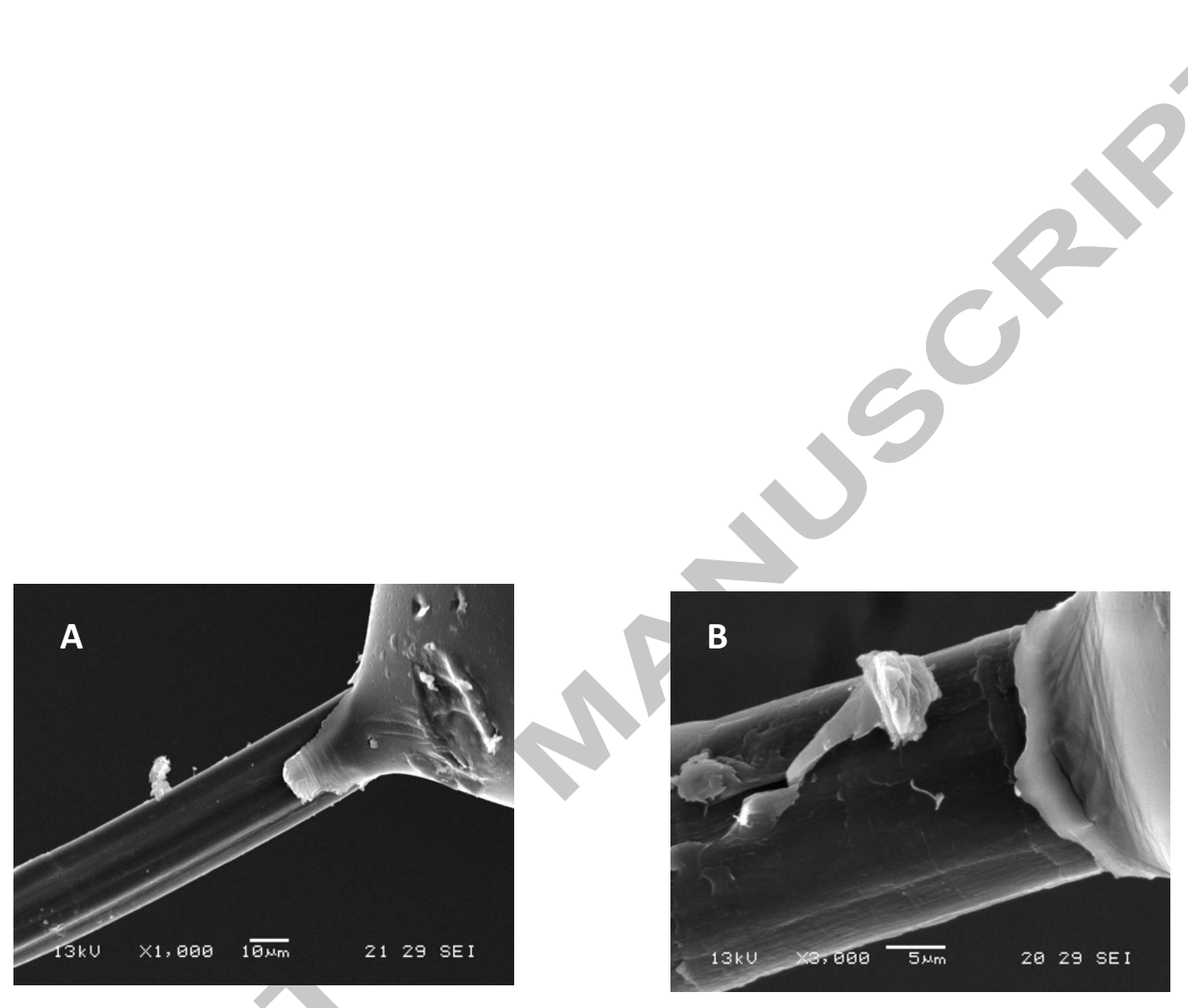

Figure 10 SEM Micrograph of debonded PLLA microdroplet on single flax fibre. A Interfacial failure. B Heterogeneous cohesive failure 


\section{Table caption}

Table 1 Out-of-plane mechanical properties measured using the modified Arcan fixture.

Table 2 Damage mechanisms in PLLA/flax mat biocomposite after different loadings in Arcan tests

Table 3 Mechanical properties from tests at different scales $\left(m_{\mathrm{f}}=30 \%\right.$ except for microdroplet) : Modified Arcan, transverse tension, microdroplet debonding

\begin{tabular}{|c|c|c|c|}
\hline & Tension $\left(0^{\circ}\right)$ & Shear $\left(90^{\circ}\right)$ & Tension $/$ Shear $\left(45^{\circ}\right)$ \\
\hline Break load $(\mathrm{N})$ & $6529 \pm 266$ & $13316 \pm 370$ & $5912 \pm 408$ \\
\hline $\begin{array}{c}\text { Apparent failure } \\
\text { strength }(\mathrm{MPa})\end{array}$ & $9.4 \pm 0.4$ & $19.3 \pm 0.5$ & $8.6 \pm 0.6$ \\
\hline
\end{tabular}

Table 1 Out-of-plane mechanical properties measured using the modified Arcan fixture. 


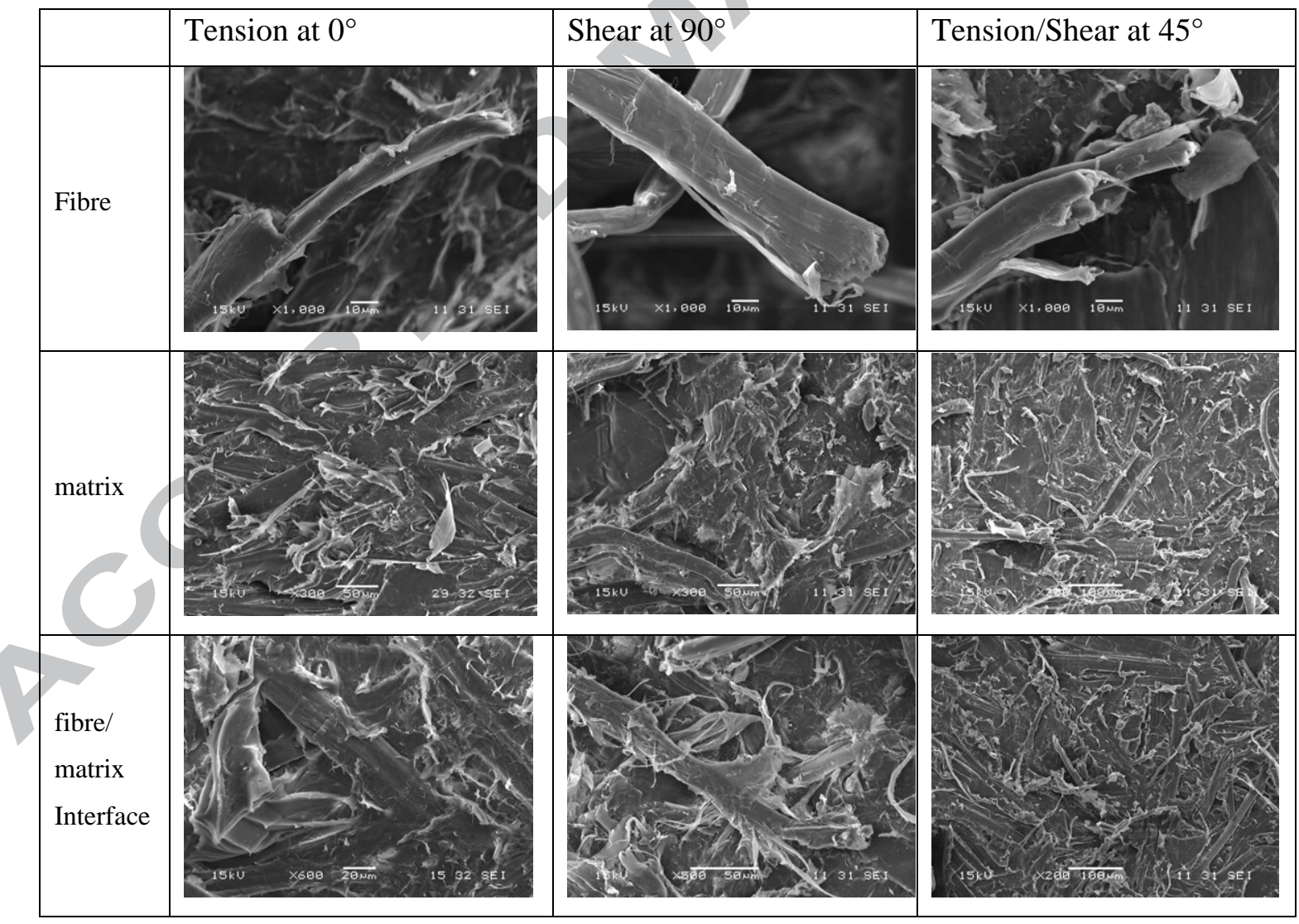


Table 2 Damage mechanisms in PLLA/flax mat biocomposite after different loadings in Arcan tests

\begin{tabular}{|c|c|c|c|c|c|}
\hline & Macroscopic & & & Mesoscopic & Microscopic \\
\hline & Tension & Tension -shear $45^{\circ}$ & Shear $90^{\circ}$ & $\begin{array}{l}\text { Transverse } \\
\text { tension }\end{array}$ & Debonding \\
\hline $\begin{array}{l}\text { Failure stress } \\
(\mathrm{MPa})\end{array}$ & $9.4 \pm 0.4$ & $8.6 \pm 0.6$ & $19.3 \pm 0.5$ & $27 \pm 3.3$ & $18.2 \pm 1.2$ \\
\hline
\end{tabular}

Table 3 Mechanical properties from tests at different scales $\left(\mathrm{m}_{\mathrm{f}}=30 \%\right.$ except for microdroplet $)$ : Modified Arcan, transverse tension, microdroplet debonding 